\title{
O CURRÍCULO DA EDUCAÇÃO PROFISSIONAL TÉCNICA DE NÍVEL MÉDIO: DESAFIOS PARA INTEGRAÇÃO
}

\author{
Maria Adélia da Costa* \\ *E-mail: adelia.cefetmg@gmail.com \\ Departamento de Educação do CEFET-MG, Brasil \\ DOI: 10.15628/rbept.2020.7948
}

Artigo submetido em nov/2018 e aceito em jan/2020

\section{RESUMO}

Este texto apresenta percepções discentes sobre o desenvolvimento do currículo integrado no Curso Técnico de uma instituição pública de educação profissional. Alunos, professores e o coordenador do curso informaram a parte empírica da pesquisa cujos dados foram acessados por meio de entrevista semiestruturada e notas de campo da pesquisadora. Foi possível observar que o currículo integrado ainda é um desafio uma vez que há limites no diálogo entre as áreas de conhecimento afins e, sobretudo, entre a formação geral e a formação específica. Prevalece a lógica fundante e estruturante dos currículos, apresentados como "grades" limitadas pela linearidade dos saberes a serem ensinados na escola o que engessa as possibilidades de uma ação docente integradora e desafiam uma formação integrada, politécnica.

Palavras-chave: Currículo integrado. Educação profissional técnica de nível médio. Formação integrada.

\section{THE CURRICULUM OF AVERAGE TECHNICAL PROFESSIONAL EDUCATION: CHALLENGES FOR INTEGRATION}

\begin{abstract}
This text presents student perceptions about the development of the curriculum integrated in the Technical Course of a public institution of professional education. Students, teachers and the coordinator of the course informed the empirical part of the research whose data were accessed through a semi structured interview and field notes of the researcher. It was possible to observe that the integrated curriculum is still a challenge since there are limits in the dialogue between the related areas of knowledge and, above all, between the general formation and the specific formation. The foundational and structuring logic of curricula prevails, presented as "grades" limited by the linearity of the knowledge to be taught in the school, which engenders the possibilities of an integrating teaching action and challenges an integrated, polytechnic formation.
\end{abstract}

Keywords: Integrated curriculum. Professional technical education at the intermediate level. Integrated training. 


\section{PONTO DE PARTIDA}

O foco deste trabalho será refletir sobre o currículo na perspectiva da integração dos conhecimentos da formação propedêutica com a formação profissional. Em 1909, quando o Estado assumiu o ensino profissional por meio

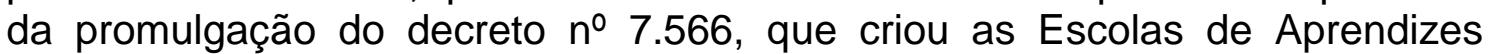
Artífices, o ensino técnico se materializou por meio de uma organização dual que concentrou de um lado as escolas de formação acadêmica-propedêutica destinada a burguesia e de outro, as escolas de formação técnica para os filhos dos trabalhadores.

Braverman (1981, p. 113), afirma que a "separação entre mão e cérebro é a mais decisiva medida simples na divisão do trabalho tomada pelo modo capitalista de produção". Costa (2016) analisa que o território da formação geral, acadêmica, propedêutica é fortemente definido cabendo à formação técnica, à educação profissional, um status periférico no sistema educacional brasileiro.

Colaborando com essas ideias Kuenzer (2007), conclui que a formação de trabalhadores no Brasil constituiu-se a partir da dualidade estrutural, uma vez que havia uma nítida marcação da trajetória educacional dos que iriam desempenhar funções intelectuais e instrumentais e os que iriam desenvolver as atividades de planejamento e supervisão.

As políticas da educação profissional, desde 2004 com o decreto № 5.154, têm induzido a modalidade integrada que é oferecida somente a quem já tenha concluído o ensino fundamental, sendo o curso planejado de modo a conduzir o aluno à habilitação profissional técnica de nível médio, na mesma instituição de ensino, contando com matrícula única para cada aluno (BRASIL, 2004).

Frente a essas considerações, tem-se o objetivo de compreender 0 processo de materialização do currículo integrado, as percepções e as negações, ou não, de conteúdos e de recortes culturais dos sujeitos, docentes e discentes, diretamente envolvidos no curso técnico integrado de uma instituição pública de educação profissional.

\section{A PESQUISA}

Nessa pesquisa utilizou-se o método qualitativo que segundo Marconi \& Lakatos (2008, p. 269):

[...] difere do quantitativo não só por não empregar instrumentos estatísticos, mas também pela forma de coleta e análise dos dados. A metodologia qualitativa preocupa-se em analisar e interpretar aspectos mais profundos, descrevendo a complexidade do comportamento humano. Fornece análise mais detalhada sobre as investigações, hábitos, atitudes e tendências de comportamento. 
A opção por esse método foi embasada na finalidade de se buscar compreender o comportamento dos seres sociais frente ao desenvolvimento do currículo integrado. A pesquisa foi realizada em três fases. Na primeira realizou-se um levantamento bibliográfico no banco de dissertações da CAPES e no Google Acadêmico com os descritores: Currículo Integrado e Educação Profissional Técnica de nível Médio. O retorno dessas publicações foram importantes para a fundamentação teórica e reorganização do planejamento da investigação.

A fase dois se estruturou a partir da definição dos instrumentos para a coleta de dados, uma vez que os sujeitos a serem pesquisados estavam definidos, a saber: alunos da EPTNM; professores da formação geral e da formação técnica; e coordenador do curso. Optou-se por aplicar a entrevista por considera-la mais apropriada à finalidade de coletar as percepções sobre a materialização do currículo integrado. Além disso, embora a entrevista possa causar constrangimento ao entrevistado, considera-se que esse recurso é mais adequado porque permite ao entrevistador conduzir o diálogo a fim de se obter a resposta para a sua indagação.

Para Giroux (1987, p. 98), as vozes que se apresentam na escola podem emergir de três diferentes esferas: aquela que corresponde à posição dos estudantes, à dos professores e a correspondente à da própria escola. Portanto, capturar essas diferentes vozes na configuração de um texto investigativo, a partir de representações que devem ser analisados, não como opostos, mas como interações de práticas dominantes e subordinadas que se modelam umas às outras na constante luta por poder, significado e autonomia.

Nessa pesquisa as vozes que ecoaram foram de cinco alunos, dois do $2^{\circ}$ ano e três do $1^{\circ}$ ano, todos indicados pelos colegas, sendo dois deles, líderes de turma. Na esfera docente o diálogo ocorreu com quatro professores, três da formação geral e um da formação técnica.

No terceiro momento foi realizado o contato pessoal com os sujeitos da pesquisa informando do projeto e convidando-os a participarem livremente. Foram três professores entrevistados e o coordenador de um curso técnico integrado. Foram dez alunos participantes, todos do $2^{\circ}$ ano e alunos dos professores respondentes.

\section{ASPECTOS TEÓRICOS E CONCEITUAIS SOBRE CURRÍCULO}

O currículo representa a expressão da função socializadora da escola. É um instrumento fundamental para que se possa compreender os componentes e as decisões diversas no âmbito político-pedagógico e administrativo, de controle sobre o sistema escolar (SACRISTÁN, 2000).

À palavra currículo pode-se associar diferentes concepções que se relacionam a fatores socioeconômicos, políticos e culturais, o que contribui para que ele seja entendido como: 
(a) os conteúdos a serem ensinados e aprendidos; (b) as experiências de aprendizagem escolares a serem vividas pelos alunos; (c) os planos pedagógicos elaborados por professores, escolas e sistemas educacionais; (d) os objetivos a serem alcançados por meio do processo de ensino; (e) os processos de avaliação que terminam por influir nos conteúdos e nos procedimentos selecionados nos diferentes graus da escolarização (MOREIRA; CANDAU, 2008, p. 17).

No currículo se agregam as experiências e os saberes que se desdobram em torno do conhecimento, em meio a relações socioculturais que contribuem para a construção das identidades dos alunos e também dos professores. Ou seja, nele pode-se perceber a interferência da e na subjetividade dos sujeitos enquanto seres socioculturais. Currículo associa-se, assim, ao conjunto de esforços pedagógicos desenvolvidos com intenções educativas (MOREIRA e CANDAU, 2008).

O currículo, na perspectiva crítica, possibilita compreender que as práticas pedagógicas se interagem com as práticas sociais e que compete ao educador verificar as injustiças nelas existentes (PACHECO, 2000). No currículo em ação deverá a escola se atentar para as diferentes identidades sociais dos sujeitos ao qual este currículo se dirige. Portanto, há que se valorizar a cultura, a diversidade de raça, de gênero, a etnia, a sexualidade, o contexto histórico e sócio-político em que se encontram os atores sociais.

A Figura 1 foi elaborada por Sacristán (2013) e representa o processo de desenvolvimento do currículo. Observa-se que a materialização do currículo em um ambiente escolar é um movimento constituído de seis fases. Todas são importantes para o ensino-aprendizagem. Destaca-se nesta organização o papel fundamental de interferência do sujeito/professor.

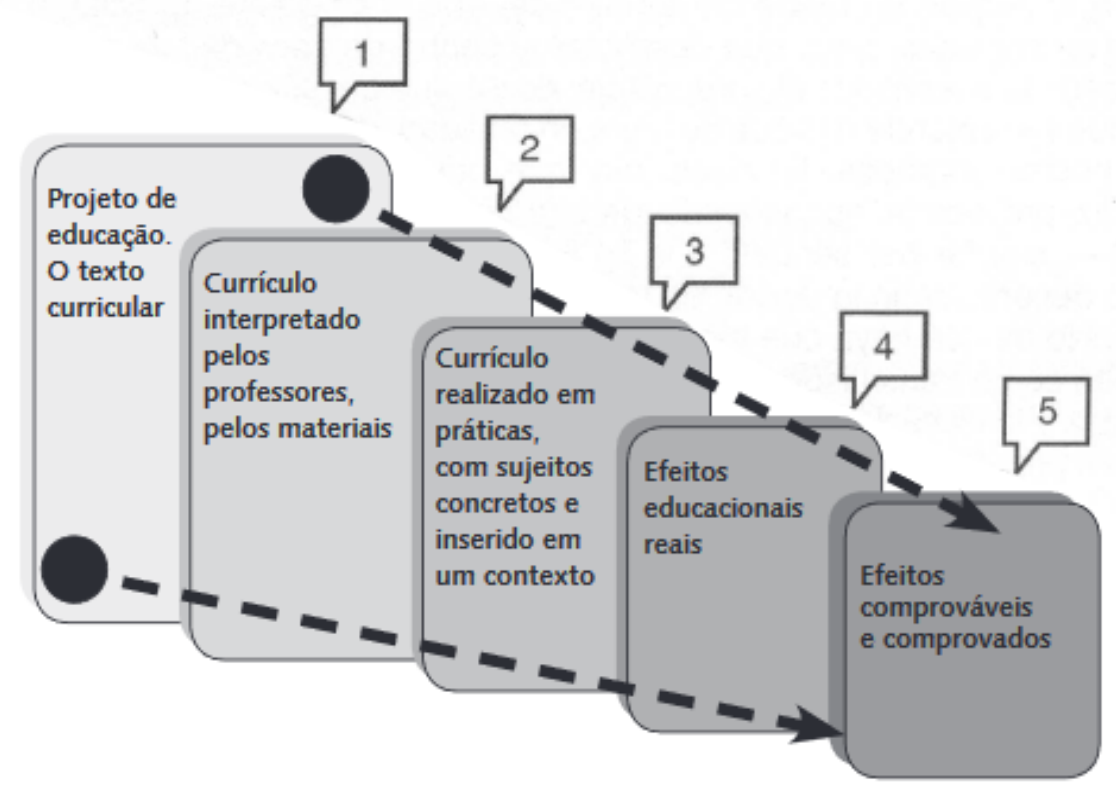

Figura 1: Esquema de concepção do currículo como processo e práxis.

Fonte: Sacristán, (2013). 
O currículo prescrito, fase 1, é elaborado pelos órgãos governamentais, visando atender ao que se considera relevante para a educação do País. Após ser organizado é apresentado aos professores, fase 2, por meio de legislação como os Parâmetros Curriculares Nacionais (PCN's) e as Diretrizes Curriculares Nacionais (DCN's). São reproduzidas em manuais ou livros didáticos, que por vezes torna-se o único currículo que o professor conhece, sobretudo na educação básica.

Nessa cadeia hierárquica, tem-se o currículo em interação com os professores e com os alunos, fase 3. Nessa fase é possível modelar o currículo conforme as concepções, crenças e ideologias dos docentes, bem como em relação a função social da escola. Posteriormente é avaliado pelos órgãos governamentais por meio de sistema de avaliação externa como o SAEB, ENEM, ENADE, dentre outros instrumentos e programas de avaliação.

É importante ressaltar que a cadeia representada na Figura 1 é influenciada e, ao mesmo tempo, influencia a vida dentro e fora da escola em suas dimensões econômica, social, cultural, política e administrativa.

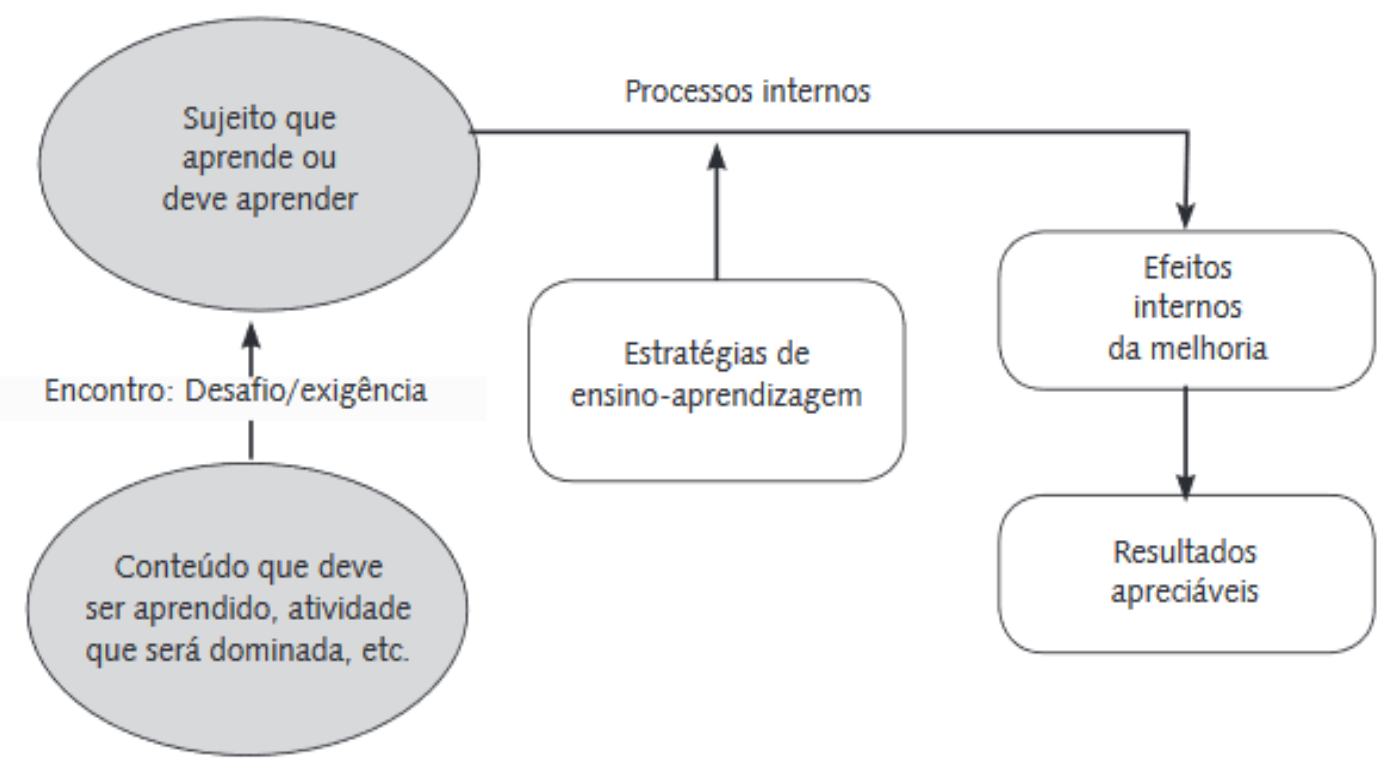

Figura 2: A dinâmica da subjetivação do currículo.

Fonte: Sacristán, (2013).

Sobre a subjetivação do currículo, o autor diz que esses processos internos e seus resultados sobre o aprendiz têm sido reconhecidos de maneiras muito distintas e com denominações variadas como:

alcance da perfeição (areté, para a cultura clássica grega), formação geral (da personalidade e da mente), erudição do pensamento, aquisição de condutas, domínio de habilidades e competências, pensamento reflexivo, memorização, construção 
de significados, aprendizagem relevante, adoção de valores, desenvolvimento da capacidade crítica, assimilação cultural, instrução, disciplina, autocontrole, dentre outros. (...) esses resultados são êxitos do sujeito, os quais, em certos casos e sob determinadas circunstâncias, podem ser vistos externamente. Podemos observar como se desenvolve a habilidade de dirigir um automóvel, mas não o processo de formação de motoristas responsáveis (SACRISTAN, 2013, p. 30).

Importante refletir sobre qual é o processo de formação profissional que, nós professores, desejamos desenvolver. Qual a função social dessa formação? Formar para o trabalho, mas qual trabalho?

Visando à aproximação do campo teórico com o empírico, registra-se a fala de um professor pesquisado, em que se pode constatar um jeito próprio de moldar o currículo ao apresentá-lo aos alunos. Este molde ou recorte é fruto de suas crenças, valores, cultura e concepções, pois o ato de ensinar depende, também, da subjetividade do sujeito que ensina.

Eu tiro tudo que não é relevante, usual. Existem várias
concepções da necessidade do conteúdo na nossa
Coordenação. Alguns professores acham que é importante os
alunos lerem, outros acham que é importante falarem, outros
acham que devem saber ler manual técnico. Cada um faz de
um jeito. Cada um enfatiza um tipo do conhecimento
(PROFESSOR ENTREVISTADO).

O relato aponta para a modelagem do currículo como resultado da seleção do conhecimento considerado importante para ser ensinado em sala de aula. Desse modo, entende-se que o professor tem o poder de ressignificar o currículo conforme as suas concepções e as suas crenças. No currículo em ação o poder de seleção, de decisão do que ensinar é do professor.

\section{O CURRÍCULO INTEGRADO}

A expressão currículo integrado tem sido utilizada como forma de contemplar uma compreensão global do conhecimento e de promover maiores parcelas de interdisciplinaridade na sua construção. A integração ressaltaria a unidade que deve existir entre as diferentes disciplinas e formas de conhecimento nas instituições escolares (SANTOMÉ, 1998).

A integração exige que a relação entre conhecimentos gerais e específicos seja construída continuamente ao longo da formação, sob os eixos do trabalho, da ciência e da cultura (RAMOS, 1995). O currículo integrado visa à superação da fragmentação, compartimentação e estratificação dos saberes; visa à integração entre a formação acadêmica, formação geral, e a formação profissional, formação para o trabalho, tendo por finalidade a superação do 
currículo para o cérebro e o currículo para as mãos, Goodson (1997), o que requer o reconhecimento do trabalho como princípio educativo.

Para Ciavatta e Ramos (2012, p. 309-310):

O currículo integrado - ou o currículo do ensino médio integrado - destaca a organização do conhecimento como um sistema de relações de uma totalidade histórica e dialética. Ao integrar, por um lado, trabalho ciência e cultura, tem-se a compreensão do trabalho como mediação primeira da produção da existência social dos homens, processo esse que coincide com a própria formação humana, na qual conhecimento e cultura são produzidos. O currículo integrado elaborado sobre essas bases não hierarquiza os conhecimentos nem os respectivos campos das ciências, mas os problematiza em suas historicidades, relações e contradições.

Silva et al (2016, p. 10) diz que "se as ações humanas se materializam a partir de práticas concretas, as práticas cotidianas na sala de aula apresentamse então como um espaço/tempo privilegiado para a mobilização de saberes individuais e coletivos - saberes que agem, que pensam, que teorizam, que constroem e reconstroem".

Esses autores complementam essa ideia afirmando que no "currículo integrado, a interdisciplinaridade desponta como um modo de fazer, uma artesania coletiva, voltada à potencialização da formação geral, técnica, intelectual e cidadã dos educandos, visando que estes se reconheçam como sujeitos da história" (Ibid., p. 11).

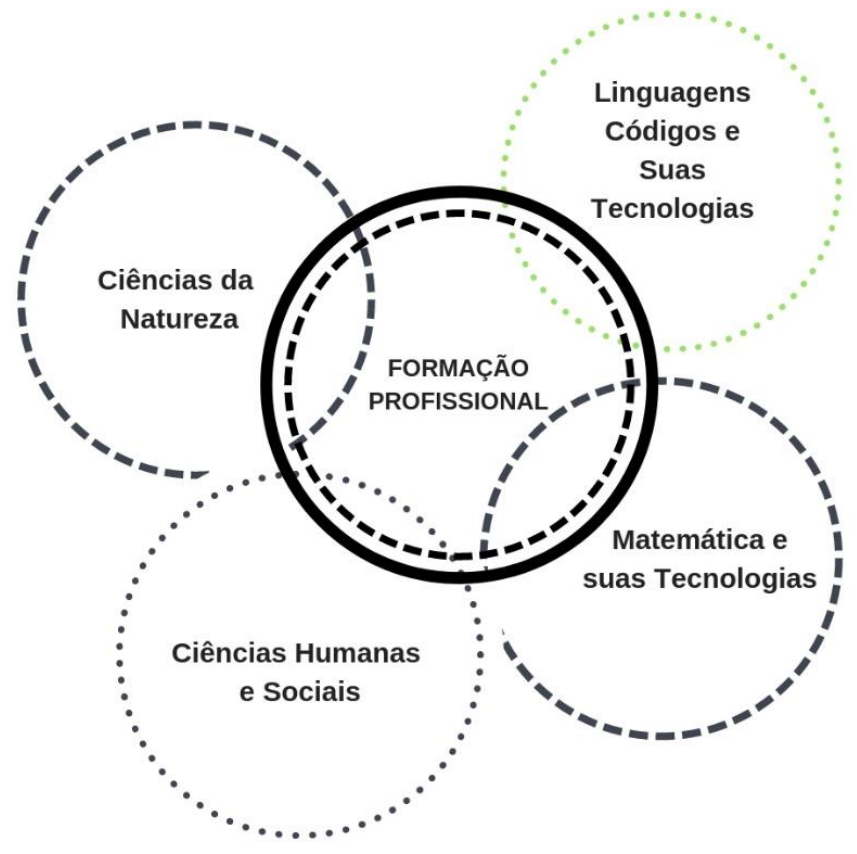

Figura 3: Currículo integrado

Fonte: Elaborado pela autora 
Apresenta-se na Figura 3 alguns aspectos que se integram na composição do currículo integrado. Na educação profissional técnica de nível médio, na modalidade integrada, a finalidade é a formação profissional dos estudantes, habilitando-os para uma profissão. Contudo, embora seja esse o objetivo dessa formação, na perspectiva da integração, entende-se que é necessário a conexão dos saberes das ciências, das artes, das culturas, do campo social e político.

Essa compreensão é balizada na crença de que a educação se constitui num processo em que se pressupõe a relação dos sujeitos sociais com a comunidade em que se está inserido, numa interlocução com o mundo social, político e cultural.

Young (2007, p. 1297) argumenta que não há nenhuma utilidade para os alunos em se construir um currículo em torno de sua experiência, para que este currículo possa ser validado e, como resultado, deixá-los sempre na mesma condição. Desse modo, a valorização dos saberes dos alunos é importante como ponto de partida para alçar voos em espaços nunca antes visitado. Por meio do currículo integrado o aluno poderá com um único bilhete de passagem conhecer espaços múltiplos de saberes e áreas científicas interdisciplinares.

Portanto, entende-se que o currículo integrado é uma forma de promover o diálogo entre as diversas áreas do conhecimento, possibilitando a formação integral dos sujeitos, de forma que possam se compreender no mundo, abandonando a perspectiva estreita de formação para o mercado de trabalho.

Nessa perspectiva, Giroux (1997, p. 163), argumenta que é essencial que as práticas pedagógicas possam colaborar com a categoria de um intelectual transformador, portanto, emerge a necessidade de tornar 0 pedagógico mais político e o político mais pedagógico. Tornar o pedagógico mais político significa inserir a escolarização diretamente na esfera da política, argumentando-se que as escolas representam tanto um esforço para definir-se o significado quanto uma luta em torno das relações de poder.

\section{PERCEPÇÕES ACERCA DA ORGANIZAÇÃo DO CURRÍCULO INTEGRADO}

Alunos e professores foram questionados sobre a percepção da integração curricular no Curso Técnico investigado. De modo generalizado os relatos mostram que o currículo não é conversado o que os leva a crer que quem elabora o Planejamento é que faz a Integração.

Morin (2000, p. 106) alerta para o risco que a organização disciplinar fragmentada traz para a educação, pois, acarreta um perigo de hiperespecialização e um risco de 'coisificação' do objeto, que transforma a disciplina como uma coisa autossuficiente; assim as ligações e solidariedades desse objeto com outras disciplinas serão negligenciadas, bem como as ligações com o universo do qual ele faz parte. 
Todos os alunos pesquisados afirmaram não perceberem a integração curricular no desenvolvimento dos conteúdos e das atividades propostas pelo professores do Curso. No entanto, os próprios alunos conseguem estabelecer conexões entre os conteúdos das diferentes disciplinas. Uma queixa posta por eles se refere ao fato da sobrecarga de tarefas e acúmulo de atividades avaliativas em um mesmo dia.

Sinceramente, eu não acho que existe integração. Eu acho que não porque já aconteceu de vários professores nem saberem o quê que um está dando. Eles não conversam entre eles porque coincidia da gente de realizar 3 a 4 trabalhos na semana porque eles resolviam dar os trabalhos todos juntos. Eu acho que se tivesse essa integração das matérias, automaticamente não haveria esses acontecimentos (ALUNO ENTREVISTADO 01).

Nossos professores são assim: muito ruim pra explicar a gente. Os professores bons são aqueles que participam junto com a gente, igual ao professor $\mathrm{X}$ de biologia. $\mathrm{A}$ de matemática também tenta ajudar a gente, a de física tenta, mas tem muita técnica na cabeça dela, daí confunde a gente (ALUNO ENTREVISTADO 03).

A percepção desse aluno é um indicativo do que ocorre no cotidiano das aulas. No entanto, transferir para os professores a responsabilidade única pela integração curricular seria perverso à medida que a cultura da escola é uma cultura desintegrada. Pelos relatos dos pesquisados e, considerando as observações registradas no diário de bordo, percebe-se que a forma de organização escolar pode ser um fator limite dessa integração.

É necessário considerar os espaços e tempos dos sujeitos na organização escolar. Além disso, torna-se fundamental fomentar momentos de convivência e de planejamento escolar para que as possibilidades da integração sejam possíveis. As ilhas que se constituem por coordenações de áreas afins é uma fronteira que se forma para a integração.

Com este desenho organizacional tem-se a seguinte situação: os professores se agrupam por áreas de conhecimentos, assim, o professor de física está na mesma coordenação que o professor de biologia, no entanto, não tem nenhum contato com os demais professores das outras diferentes áreas, sejam elas da formação geral ou da formação técnica.

Por outro lado, o Coordenador do Curso trabalha no limite de sua coordenação o que o desafia a buscar a interlocução com as coordenações de áreas onde se agrupam os professores das disciplinas da formação geral que compõem o currículo do curso que coordena. Para o coordenador existe uma desintegração em todos os cursos da instituição. [Ele] enfatiza que a integração é um problema para a Instituição e não apenas para o Curso. Aponta a organização da escola como um fator desfavorável à integração curricular, uma vez que não se propicia instâncias de interação entre os sujeitos da escola. Ou seja, não existem políticas institucionais integracionistas 
e dialógicas que visem à integração curricular. Aponta ainda, a falta de diálogo entre as coordenações de curso e de área como um limite na integração.

O diálogo é mínimo. $E$ isso é uma questão que gera o desamparo dos alunos porque eles não têm a quem recorrer. No médio, não tem uma gerencia de médio. Eu tentei, sim, o coordenador da turma, mas, eu não consegui implementar isso em função da coisa. Então, o quê que acontece? As queixas de elementos de máquina, de matérias técnicas eu consigo resolver. Agora, as do médio, onde as matérias são pulverizadas em diversas coordenações, eu não consigo (COORDENADOR DO CURSO).

As formas de organização escolar podem ser percebidas, nesta pesquisa, como ilhas entre as quais o trânsito dos professores e alunos é limitado, por diferentes motivos ou razões. Além destes limites têm-se outros agravantes que podem ser verificado nos relatos de um professor da formação geral e do Coordenador do Curso.

\begin{abstract}
A integração não está acontecendo nem mesmo dentro da Coordenação. Eu não conheço nenhum outro professor desta turma, eu não conheço nenhum outro professor do curso. Nem o coordenador do curso eu conheço, é complicado, né? (PROFESSOR DA FORMAÇÃO GERAL).
\end{abstract}

Apreende-se que a escola entende que a inserção das disciplinas da formação geral e da formação técnica em uma matriz curricular única pode determinar o currículo integrado. No entanto, os dados coletados nos mostram a necessidade de se repensar a organização do trabalho da escola o que pode ser conquistado a partir da construção de políticas pedagógicas e administrativas que visem à integração curricular, como por exemplo, a elaboração do Projeto de Curso de forma democrática, envolvendo a participação da comunidade acadêmica, sobretudo a participação conjunta dos Professores e dos Coordenadores de Curso e de Área.

Pressupõe ainda, a concepção de formas menos assimétricas entre os saberes da escola e os saberes do trabalho bem como a criação de espaços que possibilitem a interação e o diálogo entre os sujeitos-docentes, para que possam partilhar as angústias, as incertezas, mas, sobretudo, que possam celebrar o encontro entre educadores e os diferentes saberes, crenças, valores, concepções, que envolve o ofício da docência. Freire (1996, p.135) alerta que ensinar exige disponibilidade para o diálogo.

Minha segurança não repousa na falsa suposição de que sei tudo, de que sou o "maior". Minha segurança se afunda na convicção de que sei algo e de que ignoro algo a que se junta a certeza de que posso saber melhor o que já sei e conhecer o que ainda não sei. Minha segurança se alicerça no saber 
confirmado pela própria experiência de que, se minha inconclusão, de que sou consciente, atesta, de um lado, minha ignorância, me abre, de outro, o caminho para conhecer.

Destaca-se que a humildade pedagógica (CORTELLA, 2017), o reconhecimento de que eu não domino todo conhecimento e que esse conhecimento se deforma e forma em sintonia com a ciência, a tecnologia, a cultura, a política, é fundamental para que o professor esteja predisposto ao diálogo entre os pares, bem como com seus alunos. Assim, o docente estará receptível a se reinventar como um profissional do saber.

Interessa ressaltar que, para um professor pesquisado, as forma como o currículo se apresenta para o curso técnico atendem aos pressupostos da integração. Para ele, a integração é deficitária no que tange à profissionalização docente. Em suas palavras:

\begin{abstract}
A forma como o curso está organizado eu não acho ruim, não, pelo menos a forma estanque, aquela grade de disciplinas, conteúdos. Eu acho que o problema está nos professores, no como os professores estão sendo guiados, como as coordenações trabalham a integração, como que os professores viabilizam esse currículo, eu acho que o currículo não é conversado (PROFESSOR ENTREVISTADO FORMAÇÃO TÉCNICA).
\end{abstract}

Arroyo (2004) afirma que quando os professores situam as inovações nas diversas práticas do cotidiano de sua ação captam sua complexa riqueza educativa, vão entendendo que o currículo não pode ser reduzido a um documento estático a ser cumprido. Daí que, nessas experiências, não se coloca o currículo como problema nem como solução. Ele vai ao reencontro, a ressignificação da totalidade das práticas educativas da escola. O que condiz com o ato de refletir sobre a própria prática. Refletir sobre os desafios e as possibilidades do trabalho coletivo para realizar a integração.

Nessa pesquisa se constata a ocorrência da integração ao nível dos alunos.

Os conteúdos têm a ver uns com os outros, ainda mais algumas matérias de Química e Física tem a ver com as matérias técnicas tipo Metrologia. Mas o professor de Metrologia não sabe nada que o professor de Química e de Física estão dando. Eu acho que quem elabora o planejamento é que já faz integrado (ALUNA ENTREVISTADA 02).

Eu vejo muita coisa que tem a ver umas com as outras. Por exemplo, a Química daqui é muito importante pra eu entender a disciplina Tecnologia dos Materiais (ALUNO ENTREVISTADO 03). 
Interessante observar que o fio condutor da integração é perceptível no olhar do aluno sobre a escola. A aluna consegue realizar a integração dos conteúdos escolares, além de também, conceber que uma possibilidade da integração está sob a responsabilidade de quem organiza o currículo. A integração em sala de aula é tão distante das práticas docentes que leva a aluna a concluir que a integração é (im)posta por quem organizou o currículo.

Vasconcellos (1992, p. 15) diz que o processo educativo, na perspectiva dialética, considera que o educando, tendo percorrido as etapas anteriores de aproximação e análise do objeto de conhecimento, deve ter oportunidade de sistematizar o conhecimento que vem adquirindo e expressá-lo concretamente, seja de forma oral, gestual, gráfica/escrita ou prática. Assim, o aluno assume um protagonismo nesse processo de ensinar e aprender.

$\mathrm{Na}$ voz discente, o relato é fortemente marcado pela falta de interação e de diálogo entre os docentes do curso, uma total ausência da dialética colocando o aluno na condição passiva e receptiva de um programa disciplinar a ser cumprido. Entretanto, essas vozes que são silenciadas no processo de aprendizagem mostram que [eles] são capazes de entender a integração mesmo quando as ações docentes são desintegradas.

\section{CONSIDERAÇÕES FINAIS}

Sobre o currículo integrado observou-se que permanece a lógica disciplinar com fronteiras bem delimitadas entre as áreas/disciplinas, com poucas chances de integração numa dimensão de currículo integrado-crítico.

Uma das tensões percebidas na forma de organização do curso incide na desintegração entre a formação geral e a formação específica, o que por conseguinte persiste uma concepção de ensino médio mais uma formação técnica. $\mathrm{O}$ que deveria ser um curso técnico de nível médio passou a ter características de dois cursos com matriz curricular única. Com todos os avanços da teoria curricular, muitas discussões ainda não chegaram aos professores. Há ainda um número expressivo de educadores que veem o currículo como uma grade de disciplinas com conteúdos pré-selecionados para serem ensinados em determinado tempo e espaço.

Apesar de toda a riqueza propiciada pela diversidade cultural existente no espaço escolar, o currículo ainda não se apropriou dela. Constata-se um rigor em relação ao cumprimento do planejamento curricular das disciplinas. Não obstante, a forma como se estrutura a organização do trabalho escolar contribui com a fragmentação do ensino ofertado. A instituição apresenta um arranjo organizacional que impõe limites bem definidos à integração curricular, como as ilhas formadas entre as Coordenações de formação geral e formação técnica.

Talvez, um alento para nós professores, que acreditamos no currículo integrado seja a constatação que a integração é realizada pelos alunos que conseguem pôr em prática múltiplas conexões tecendo a rede dos conhecimentos necessários a sua habilitação profissional. 


\section{REFERÊNCIAS}

ARROYO, Miguel. Imagens quebradas: trajetórias e tempos de alunos e mestres. Petrópolis, RJ: Vozes, 2004.

CIAVATTA, Maria; RAMOS, Marise. Ensino médio integrado. In: CALDART, Roseli; PEREIRA, Isabel; ALENTEJANO, Paulo; FRIGOTTO, Gaudêncio (org). Dicionário da Educação do campo. Rio de Janeiro: Expressão Popular, 2012.

FREIRE, Paulo. Pedagogia da autonomia: saberes necessários à pratica educativa. São Paulo, SP: Editora Paz e Terra, 1996.

FRIGOTTO, Gaudêncio; CIAVATTA, Maria; RAMOS, Marise Nogueira (orgs.). Ensino médio integrado: concepção e contradições. São Paulo: Cortez, 2005. GIROUX, H. Os professores como intelectuais. Porto Alegre: Artes Médicas, 1997.

GOODSON, Ivor. A Construção Social do Currículo. Lisboa: Educa, 1997. MOREIRA, Antônio Flávio; CANDAU, Vera. Multiculturalismo: diferenças culturais e práticas pedagógicas. Editora: Vozes, 2008.

PACHECO, José Augusto. Teoria curricular crítica: os dilemas (e contradições) dos educadores críticos. Revista Portuguesa de Educação, 2001, 14(1), pp. 4971.

RAMOS, Marise Nogueira. Do ensino técnico à educação tecnológica: (a)historicidade das políticas dos anos 90. Dissertação de mestrado. UFF, Niterói, 1995.

SACRISTÁN, José Gimeno. O currículo: uma reflexão sobre a prática. Porto Alegre: Artmed, 2000.

SACRISTÁN, José Gimeno. (Org.) Saberes e incertezas sobre currículo. Editora Penso, 2013.

SANTOMÉ, Jurjo Torres. Globalização e interdisciplinaridade: o currículo integrado. Trad. Cláudia Schilling. Porto Alegre: Artes Médicas, 1998.

YOUNG, Michel. Para que servem as escolas?. Educação e Sociedade, v. 28, n. 101, p. 1287-1302, 2007.

VASCONCELLOS, Celso. Metodologia dialética em sala de aula. Revista de Educação AEC. Brasília: abril de 1992 (n. 83). 